\title{
Knowledge Transfer in Cynefin Framework
}

\author{
Harris Turino $^{1 *}$, Adhi Setyo Santoso ${ }^{2}$ \\ ${ }^{1}$ Sekolah Tinggi Manajemen IPMI, DKI Jakarta, Indonesia 12750 \\ ${ }^{2}$ President University, Bekasi, Indonesia 17550
}

\begin{abstract}
A B S T R A C T
The Cynefin model (Kurtz \& Snowden, 2003) is a common concept for designing the most logical response from decision-makers in certain situations. This model is general, so it can be used in several applications, such as knowledge transfer, which is the focus of this article. The author aims to describe in detail, both the characteristics of the domain and the decision-making model, with the concept of causal ambiguity (Reed \& Defillippi, 1990), absorptive capacity (Zahra \& George, 2002), and pragmatic view of knowledge (Carlile, 2004). One of the managers' common mistakes in managing organizational knowledge is the failure to identify situations accurately. Using the case study method, the results of this study are expected to help practitioners minimize these mistakes and determine the right decisions in forming a sustainable competitive advantage (SCA). The discussion of this paper is divided into several sections; dynamics of cynefin model, absorptive capacity, pragmatic view of knowledge, integration of concepts, and conclusions.
\end{abstract}

ART I C L E I N F O

\author{
Article History: \\ Received : 14-09-2020 \\ Revised : :16-10-2020 \\ Accepted : 19-10-2020 \\ Published : 31-10-2020
}

Keywords:

Cynefin Model

Knowledge Transfer,

Absorptive Capacity

Pragmatic View of Knowledge

Causal Ambiguity,

Knowledge Management

Sustainable Competitive Advantage

*Corresponding Author E-mail:

harris.turino@ipmi.ac.id

Copyright $\odot 2020$ Authors. This is an open access article distributed under the Creative Commons Attribution License, which permits unrestricted use, distribution, and reproduction in any medium, provided the original work is properly cited.

\section{INTRODUCTION}

The Cynefin model distinguishes five domains based on cause and effect, namely known, knowable, complex, chaos, and disorder. Each domain has specific characteristics and a specific decision-making approach model. This domain does not describe the knowledge that individuals or organizations have. However, it explains the situation based on the perception of the individual or organization (Kurtz \& Snowden, 2003) as seen in figure 1-a.

Known and knowable that are categorized as ordered domains have predictable causality. For known, the causality is clearly defined. For 
knowable, causality is spread in the realm of time and place or has not been connected. Known domain can be represented by the word DEFINE, whereas knowable can be represented by SEPARATE. Therefore, the decision-making approach for known is a sense-categorize-respond, wherease that for knownable is sense-analyzerespond.

Complex and chaos are categorized as un-ordered domains because the interaction between variables is complicated, interconnected, or even invisible. In complex, causality can be traced with a narrative approach into a pattern (proposition) and developed gradually (emerging). As for chaos, the causality is hidden, and it is necessary to conduct a try-and-error approach to find the most capable pattern to stabilize the situation. The appropriate word to represent a complex domain is INTERTWINE, whereas chaos is HIDDEN. Therefore the logical approach for the complex is a probe [investigate]-senserespond-sense-respond, and that for chaos is act-sense-respond.

In the domain of disorder, there is a conflict of interest between parties. Decision-makers compete with each other to point to their influence on an issue, for example, researchers seeking data for research as the basis for arguments, politicians forge relationships to expand their influence, or leaders appointing their powers to exert complete control. The more important an issue leads to the greater tensile force between the parties to their respective comfort zones. In this case, the most effective approach model is to collaborate towards a shared consensus.

In the context of dynamics, movement, or displacement between domains is possible, and it needs to be realized by decision-makers. Given the many possible changes, the Cynefin model tries to illustrate it in figure- $1 \mathrm{~b}$.

Innovation and radical change are the results of the dynamics in the-un-ordered domain, because this domain brings out a wide range of patterns that is unimaginable previously. The management of one of the patterns, for example, with narrative, provides a better understanding of a knowledge and increases the flexibility of organizations in creating due to the openness of broader insights. The movement from knowable to complex (exploration) is one of the efforts to trace the new pattern. On the other hand, exploitation is an attempt to formulate the new pattern into a more standard and stable hypothesis. Generally, exploitation is followed by incremental improvement (knowable $\rightarrow$ known, and vice versa), and this is an effort to improve the quality of knowledge, or the quality of

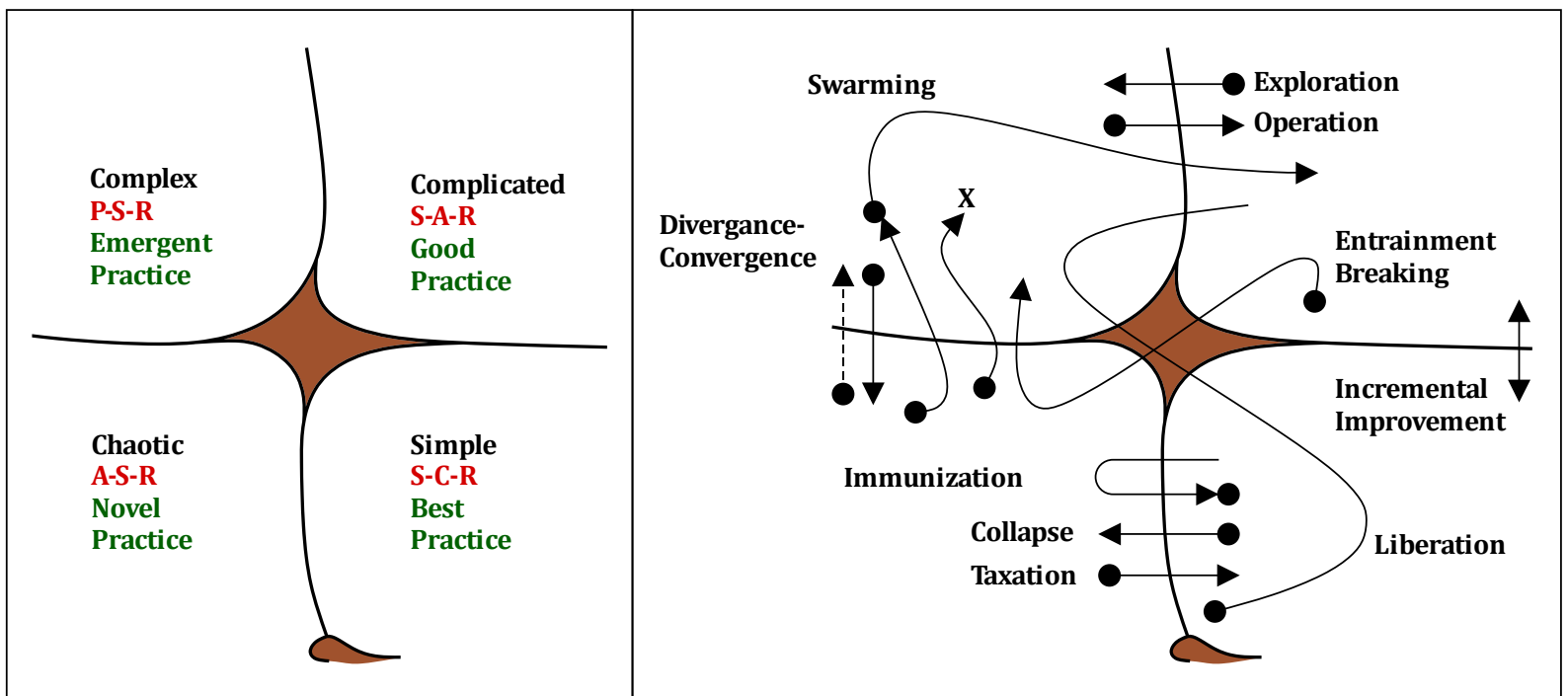

Figure-1a: Domain Cynefin

Cynefin Model (Kurtz \& Snowden, 2003)

Figure-1b: Dynamika Cynefin 
Products and services (Cho \& Pucik, 2005).

The fact that the pressures of the past tend to change the domain to move clockwise, for example, a group of strangers living together ( complex ), will interact with each other, cultivate beliefs and ideas together( knowable) until it develops into a norm, culture, and ritual (known) (Kurtz \& Snowden, 2003). Instead, the pressures of the future tend to move the domain from right to left. For example, a leader with a known rule will be replaced by a younger generation who tend to be more energetic to make changes (knowable), or even break the old tradition of radically seeking a new form of more ideal (complex or chaos) (Kurtz \& Snowden, 2003).

In reality, organizations tend to move clockwise toward stability (known). It is seen with the increasing standardization in all areas with the aim of efficiency and consistency. But it was the change in the situation that then forced the organization to move in the opposite direction. Thus, there is an oscillation movement between domains. In this paper, we describe in detail the characteristics of cynefin domain and its decision -making model with the concept of causal ambiguity, absorptive capacity, and pragmatic view for the absorption of organizational knowledge to produce innovation. By using knowledge transfer concepts that are easier to understand, cynefin models can be more specific.

\section{THEORETICAL FOUNDATION}

\section{Absorptive Capacity}

Absorptive capacity is the organization's ability to claim, assimilate, transform, and exploit knowledge into a sustainable competitive advantage (Zahra \& George, 2002). Acquisition is an ability to identify and collect new knowledge; assimilation is the organization's ability to analyze, interpret, and understand new knowledge gained at the time of acquisition; transformation is an ability to develop knowledge assimilation results, facilitate the formation of a combination with existing knowledge, integrating, and knowledge to accommodate all of the interests within the organization. The result of the transformation is a new standard knowledge that is ready to be implemented. Exploitation is the ability to use and implement transformed knowledge into an organization operational to produce commercial ends.

When compared to the definition of exploitation of cynefin model, then exploitation according to absorptive capacity can be interpreted as the implementation of innovation results by improving the quality of commercial ends continuously until the emergence of emerging innovations. From this point, it appears that the concept of absorptive capacity emphasizes a oneway process to produce innovation and does not discuss how it is related to the next innovation (iteration).

Acquisition and assimilation capabilities are grouped as potential absorptive capacity (PACAP) because it does not impact SCA. For the opposite reason, transformation and exploitation capabilities are grouped as realized absorptive capacity (RACAP). The comparison between RACAP and PACAP is called the efficiency factor, which shows the organization's efficiency in converting the knowledge into SCA, whose ultimate goal is performance improvement (Zahra \& George, 2002).

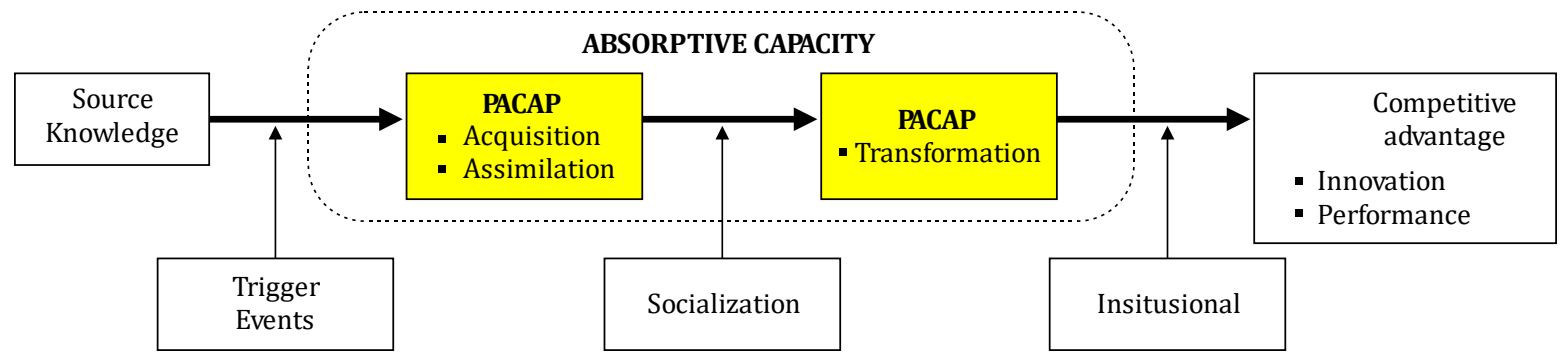

Figure 2. Absorptive Capacity Model (Zahra \& George, 2002) 
The absorptive capacity model in figure- 2 is a conversion system from raw knowledge that the organization originally did not have into output in the form of SCA. There are three factors influencing the success of the process, namely, trigger events, socialization mechanisms, and institutional. The event of triggers, such as regulatory changes, new technologies, poor organizational performance, increases the organization's efforts to acquire knowledge. The more radical trigger event can lead to more intensive acquisitions, and it generally accompanied by the allocation of additional resources.

Socialization mechanisms affect organizational efficiency factors because they can increase or reduce the gap between PACAP (assimilation) and RACAP (transformation). Mintzberg (1980) said that effective socialization mechanisms are adapted to its organizational structure, such as standardization of work process in machine bureaucracy and mutual adjustment on adhocracy. The more effective the socialization mechanism, the higher the efficiency factor.

Institutional is the norm, formal and informal, that affects the organization's ability to protect its innovation or competitive excellence. In a highly institutional environment, the organization has the opportunity to patent its innovation so that the effort of imitating (copycat) from the other party requires a high cost and effort. But when institutional is low, organizations tend to isolate mechanisms such as maintaining the confidentiality of procedures, techniques, information, and so on (Zahra \& George, 2002).

From the description above, it can be concluded that in PACAP, there is a collection of accumulated knowledge, where the more varied the knowledge (and still related), the more flexible the organization in designing its innovation configuration so that the effort and cost required by the organization are relatively cheaper. From PACAP, the knowledge is converted to RACAP, and finally, it forms SCA. If competitive advantage is directly affected by RACAP, its sustainability characteristics are influenced by PACAP (Zahra \& George, 2002).

\section{Pragmatic View of Knowledge}

Another perspective in describing the effort of knowledge development towards innovation and SCA is formulated by the Pragmatic View of Knowledge (Carlile, 2004). If the absorptive capacity (Zahra \& George, 2002) focuses on how knowledge flows in the innovation process, the pragmatic view emphasizes the characteristics of knowledge in each process and categorizes it into three boundaries, namely, syntactic, semantic, and pragmatic. These two perspectives are not contradictory but rather complementary.

There are three variables used to describe each boundary, namely, (1) the level of novelty, the number of new things in the knowledge environment, (2) specialization, specific knowledge in each function or section, and (3) dependency, the dependencies between parts of the organization. The syntactic domain occurs when novelty is low so that newly acquired information is strongly related to prior knowledge or just incremental additions. Therefore, it does not change the common lexicon of coordination between functions within the organization, and it only takes information processing (simple transfer)to adopt new information into new knowledge.

When novelty then increases, the connection and relevance of new information with prior knowledge are decreased. The information requires a new interpretation to be understood by all common meanings so that a new common lexicon will be formed (Carlile, 2002; Carlile, 2004). It is the characteristic of the semantic domain. The move to cross the line from the syntactic domain to the semantic domain is common among organizations given that the business, cost, and business risks faced are relatively not very large.

The pragmatic domain occurs at high novelty where the technology and relevance of new information with prior knowledge are small. 


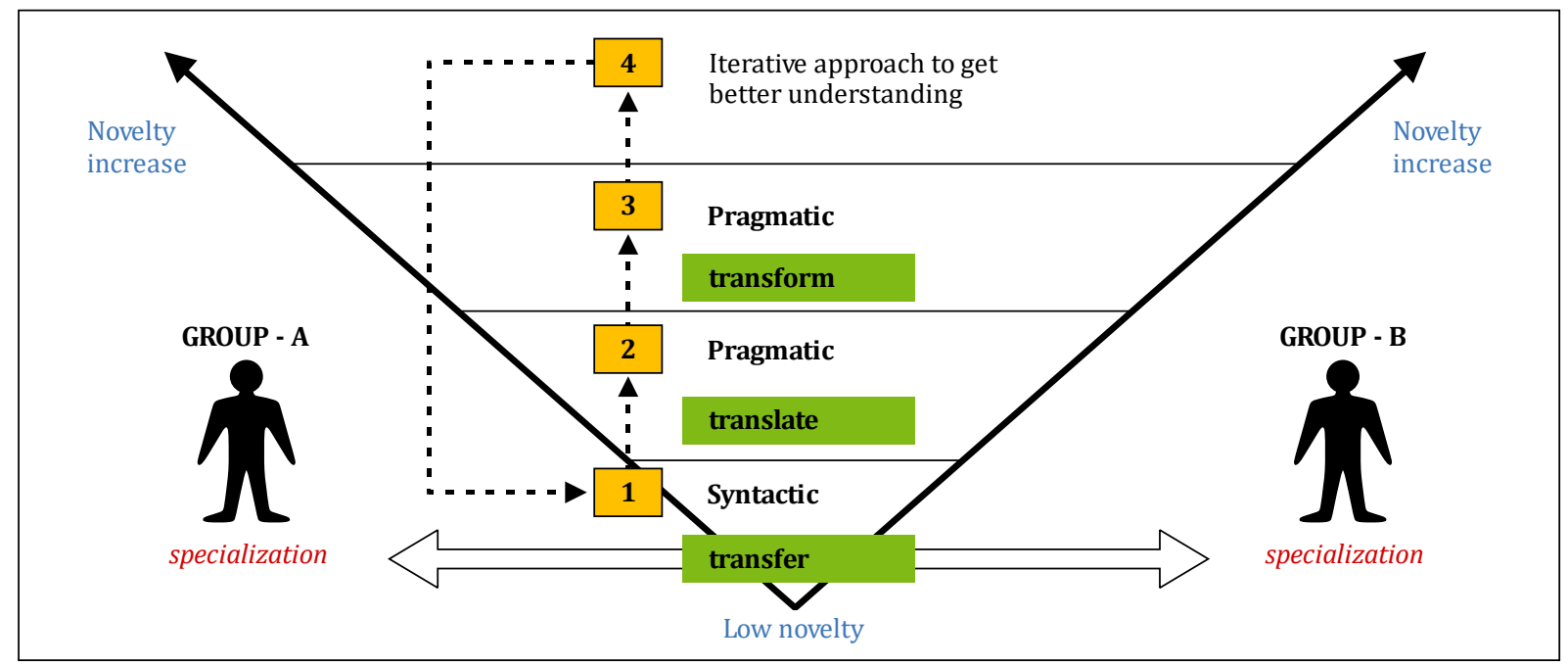

Figure 3. Pragmatic View of Knowledge Model (Carlile, 2004)

The formation of common meaning alone is not enough, because the new knowledge that can be called foreign where each function has its interests that must be accommodated. Therefore, a joint consensus is needed to find an optimum point of coordination until a new standard of knowledge contains common interest (Carlile, 2002; Carlile, 2004). This new standard of knowledge then became a routine and a new common lexicon since then. Thus the process will repeat (iteration) as illustrated in Figure 3.

Innovation to build competitiveness only happens in the pragmatic domain. Moving across the boundary from semantic to pragmatic generally requires huge costs, effort, and business risk, so it is not uncommon for organizations to be reluctant to do so. Carlile (2004) further stated that the organization's capabilities are a product of the manager's knowledge capacity and ability to identify novelty and cross boundaries. Thus, the advantages of competing depend on the ability to cross the boundary to the pragmatic domain, while its sustainability depends on the willingness to do pragmatic iteration consistently.

\section{METHODOLOGY}

To provide a better understanding of the perception of the situation, the authors presented a case study that follows Yin (1991) methodology at one of Indonesia's largest financing companies, Astra Credit Companies (ACC). Sometime after the 1997 monetary crisis subsided, some banks began to pursue motor vehicle financing businesses. Initially, they only provided loans to non-bank financial institutions. Some of them are Bank Danamon, Permata, Mandiri, BCA, Bumi Putera, and so on. The banking phenomenon entering the automotive financing industry has existed since the 1990s. Bank of Tokyo (BOT) is one that is quite active even though the marketing area is only limited to DKI and Bandung. Since 2000, however, the number of banks that have jumped directly into transactions with customers has been growing. The ACC, as a market leader in the industry, sees this as momentum. The case study result from ACC is analyzed with the relevant theory and produce several propositions afterward.

\section{RESULT}

\section{Case Study}

There are two underlying reasons for ACC to use the phenomenon of the direct involvement of banks in customer transactions within the automotive sector. First, that banking does excel in terms of pricing but loses out on speed due to the conservative nature set by banking rules. On this basis, the ACC assumes that customers who can meet strict requirements and want to 'wait a relatively long process' are not much. Second, the entry of banking into the automotive financing industry is only a business portfolio strategy for over liquid banks. When the allocated 
funds are exhausted, the financing will be discontinued. Both analyses were delivered by the ACC CEO at the annual meeting in late 2000, and indeed it was proved a few months later in early 2001. The volume of financing of some banks is very small and quite slow, especially when compared to ACC which is increasing rapidly. Some banks began to stop financing in late 2000 and started again in the second quarter of 2001. Nevertheless, there are still efforts to increase marketing aggressiveness, the creation of financing packages, and for certain customers given pricing that is almost similar to banking.

The description above points out that ACC management sees the phenomenon of banking entry into the automotive financing business as a knowable domain. They only see a bank as a relationship between low pricing, prudent properties, and business portofolio. There are two things that may be missed in their analysis. First, the banking institutions that plunged into this business quite a lot. Even if the above two ACC reasons are true, basically, banking competitors never go away because when one bank stops financing, another bank interferes with the ACC market. For example, in 2001, Bank Danamon was the ACC's largest banking competitor. In 2002, the bank stopped financing as it was preparing to acquire Adira Dinamika Finance. In that year, Panin Bank and Bank Niaga took over Danamon's position. In 2002, Bank Niaga tended to decrease its aggressiveness but was replaced by KKB BCA.

Second, the ACC may not analyze more deeply that banking also conducts the learning process. In addition to pricing, they also excel in promotions, extensive networks, and customer databases. Their constraints at the time were only speed, but it was later overcomed by establishing a financing institution as one of its subsidiaries (SBU). For example, BCA established BCA Finance, which has the same low pricing and speed as non-bank institutions. BCA Finance is not a bank, but a financing institution whose shares are owned by $\mathrm{BCA}$, so banking regulations do not apply in this SBU. This step was followed by several banks such as Panin (Bank Panin) and Saseka Finance (Bank Niaga). Another unwitting effect is the rise of local banks that tend to follow fashion to form automotive financing portfolios, such as Kesawan Bank and Mestika Bank in Medan, Bank Sumsel in Palembang, and Bank Jasa Jakarta in Jabodetabek.

Experience in winning the competition with Bank of Tokyo (BOT), encouraged ACC to analyze the phenomenon of banking entry in 2000 as something common. ACC feels it has high prior related knowledge and tends only to do senseanalyze-respond. The analysis submitted by the CEO at the annual meeting is assimilation or translate effort to provide common meaning to all management ranks. But the experience of facing one foreign bank is certainly different from facing some local banks that over liquid after the crisis. The move of this group of banks tends to attract the interest and attention of the public, whose effect makes it a fashion so that a few banks are just participating.

Looking at its threatened market, ACC began to investigate and saw this phenomenon as a situation in complex domains. The entry of two banks into the automotive financing business does not mean that the ACC faces an additional two competitors, but it could attract other banks to be active. The more competitors that the bank has, the more ACC employees are "hijacked" into the bank, and the two strongholds are created, bank and non-bank financing institutions. The two strongholds cause banks to become more restrictive in joint finance cooperation with nonbank institutions, and so on. It indicates intertwine between agents or variables that characterize complex domains.

Improvement began to be done, from treasury system, recruitment, marketing, operating support, to credit process. The improvement of the credit process is one of the most radical because precisely, in terms of speed, banks are starting to be able to beat the ACC. Therefore the ACC needs to adopt new knowledge of this domain that has high complexity properties. 
The first step is to implement an online system implemented in 2003. This system allows each ACC branch and customers to access data according to its privilege in real-time. Even ACC was the first non-bank financing institution to do that. Then, ACC developed an online survey, where survey order and survey results can be sent via mobile phone, replacing the use of paper and manual data entry. The credit analysis system is centralized so that all credit analysts in the branch are drawn to the head office. Recently developed credit analysis formulas include the establishment of minimum living requirement standards, profit margin standards per business type, and red-green rules that categorize high-medium-low risk vehicles based on down payment and credit period. In obtaining such knowledge, ACC conducts best practice to GE Capital Investment, investigation/observation, and internal knowledge creation.

The application of this credit process system affects improving tacitness and specificity. The increased tacitness results in decreased specialization and increased specificity results in decreased inter-dependency between functions. In this case, the related functions are sales, surveyor, and credit analyst. Specialization of each function becomes low when compared to the new system (knowledge) applied, and the decrease in interdependency is due to the increasing ambiguity of coordination between functions with the new system.

Therefore, not only common meaning is required between functions, but also a common interest in the form of new processes, standards, and requirements. For example, for survey orders, it takes home, office data, at least two phone numbers, and approximate home/office locations. The survey process originally required a minimum lead time of 2 hours, reduced to 45 minutes (as standard). Overall, the default credit decision was originally 8 hours, changed to 4 hours for new customers, and 1 hour for repeat customer order. The new coordination, standards, and requirements do not occur immediately, but through repeated mutual influence processes taking into account the needs and interests of each function, until a mutual agreement or consensus is reached. Currently, the system has become the standard for credit processes in ACC that continuously undergo incremental improvement and support further innovation.

\section{DISCUSSION \\ Concept Integration}

Based on the ACC case study above, in the context of this knowledge management, the discussion starts from the knowledge environment (Cynefin model), knowledge characteristic, and knowledge integration (pragmatic view and absorptive capacity). As already mentioned, the domain on the Cynefin model describes the situation according to the perception of the individual or ACC organization, which is distinguished based on the causality of the agents in it (processes, actors, techniques, methods, etc.). The concept of absorptive capacity is used to describe the process of detail since knowledge is still in the environment, absorbed by the ACC organization, until the formation of innovation and SCA. While the pragmatic view is used to bridge between knowledge characteristics and each process in absorptive capacity, as seen in Figure 4.

The basic characteristics of knowledge are causal ambiguity, i.e., the uncertainty of the causal relationship between cause and effect. The higher causal ambiguity, the knowledge is harder to be transferred or reproduced (Szulanski, 1996), and it has a barrier for imitation (Lipmann \& Rumelt, 1982; Reed \& Defillippi, 1990). Causal ambiguity is influenced by three anesthesis factors, namely tacitness (Polanyi, 1967),

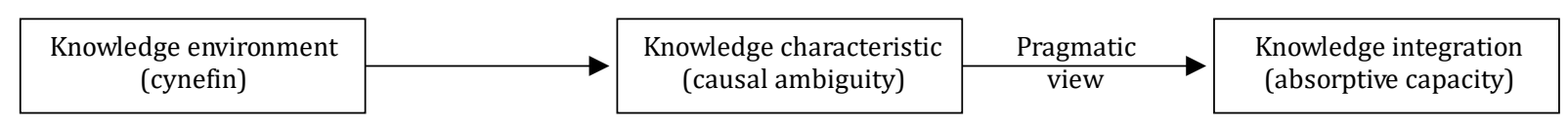

Figure 4. Concept Integration Model 
complexity (Nelson \& Winter, 1982; Barney, 1985), and specificity (Williamson, 1985). Tacitness is the size of the knowledge that cannot be encoded. Complexity shows how many interconnectedness between variables in the knowledge while specificity show attachment of knowledge in specific conditions.

The ACC case analysis in this paper uses common organizational intelligent assumptions, which means that the average expertise of the ACC organization is considered similar. This assumption does not indicate that each organization has the same innovation capability, but rather the commensurate ability to externalize (tacit -> explicit) from knowledge source and assimilation capability (understanding new knowledge) of knowledge recipients. Consequently, tacitness and specificity depend only on the high level of complexity in knowledge. This assumption becomes logical when paying attention to ACC organizations that have variations in high-skill expertise. In general, large and worldclass companies have this, so the competition between them only revolves around creativity in developing innovation towards sustainable competitive advatage (SCA).

When adopting or transferring new knowledge, the ACC organization considers that knowledge is useful or better/higher to adapt to the environment and can produce SCA in the future. When new knowledge is integrated, the low complexity of knowledge represents a high novelty for the ACC organization. As the complexity increases and tacitness increases, they indicate the change in the specialization of each function relative to new knowledge. If new knowledge is considered to have a higher level of prior knowledge, the increase of tacitness means the decrease of specialization level. In addition, the increase in complexity also affects specificity, which means coordination between functions becomes ambiguous and obscure so that it requires resetting the relationship order between the functions. Thus, a proposition can be formed:

Proposition-1: When knowledge is integrated, complexity is positively correlated with the level of novelty, tacitness is negatively correlated with specialization, and specificity is negatively correlated with interdependency.

To describe the Cynefin model in more detail with these concepts, the discussion is divided into two parts: identification of domain characteristics and identification of the decision-making model (responsive model).

\section{Domain Characteristic Identification}

In representing cynefin domains, in addition to using the words DEFINE, SEPARATE, INTERTWINE, and HIDDEN, we can use a combination of three variables, namely predictableness (predictable effect of cause), perceivable-ness (causality can be seen and understood by actors), and repeatedness (possibility repetitive causality in the future). Causality in the known domain is perceivable,

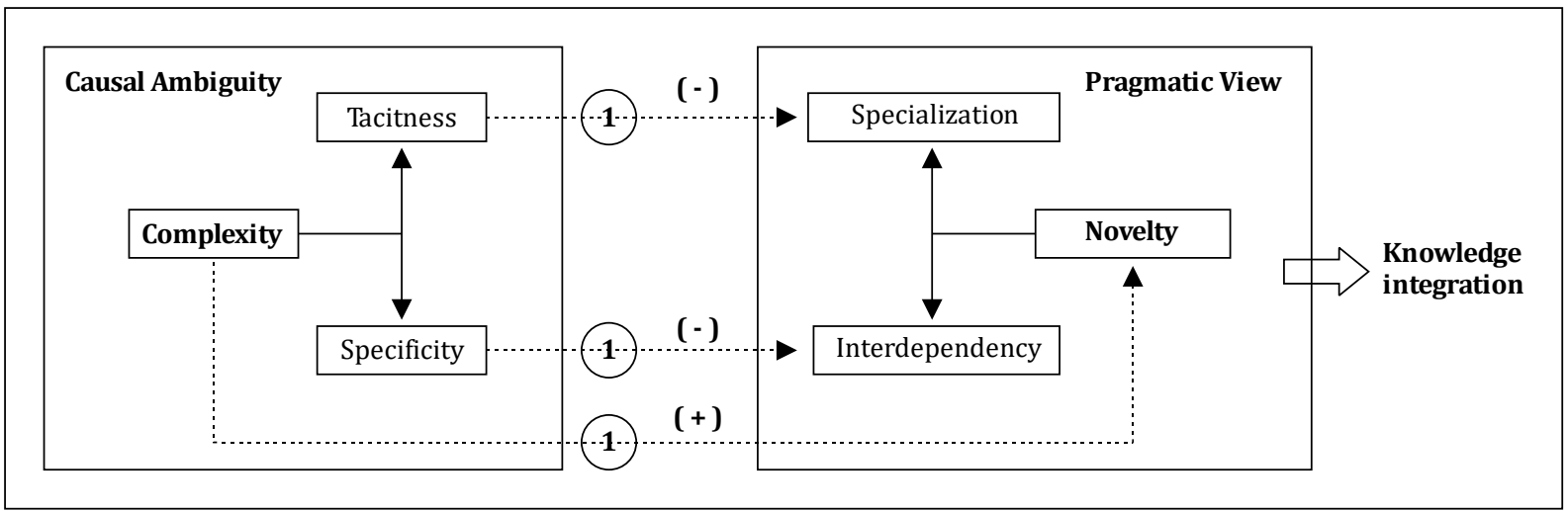

Figure 5. The Relationship Between Causal Ambiguity dan Pragmatic View of Knowledge 
predictable, and always repeated; the knowable domain is not perceivable, predictable, often repeated; the complex domain is perceivable, not predictable (retrospective coherence), rare repeated; and the chaos domain is not perceivable, not predictable, almost never repeated.

In the context of causal ambiguity, the known domain is perceivable, predictable-and always repeated, and it contains knowledge that is low complexity or simple. This nature makes ACC organizations more likely to standardize such as SOP, policy, manual. Low complexity means low tacitness and low specificity. When the knowledge is then integrated, the pragmatic view identifies this condition as low novelty because it does not change the common lexicon significantly. Therefore, a proposition can be formed:

Proposition-2: In known domains, knowledge is low complexity and is predominantly positively correlated with low novelty during integration, and it is identic with the syntactic domain.

When complexity increases but causality is still predictable, tacit knowledge increases as perceivableness decreases. It is the characteristic of knowable domains. When it is integrated, the increasing tacitness makes the specialization between functions decreases and makes the interdependency a little ambiguous. The pragmatic view identifies this situation as a moderate novelty and requires common meaning to increase specialization and clarify interdependency. The propositions are:

Proposition-3: In knowable domains, knowledge is moderate tacitness and moderate specificity due to the increase of complexity, and this is synonymous with semantic domains.

When complexity continues to increase and reach high or very high levels, causality becomes unpredictable due to increased tacitness and specificity that also reaches high levels. If causality still has perceivableness, then this is a complex domain according to cynefin or pragmatic model according to pragmatic view. But when perceivableness is invisible (hidden), at least according to the majority of individuals, then the situation is in the domain of chaos. This conception is presented in Figure 6.

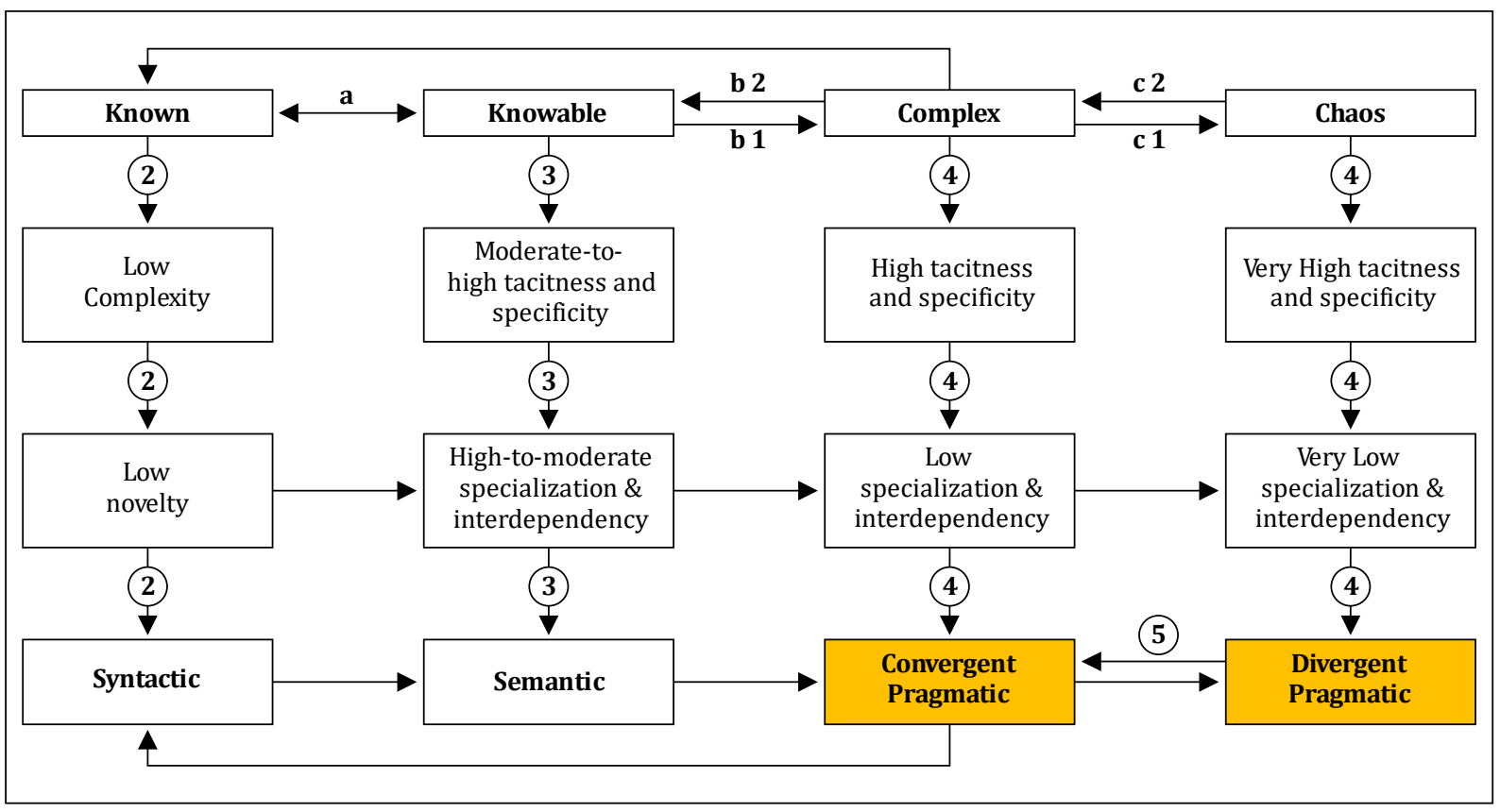

Figure 6. Domain characteristic identification model 
In the pragmatic domain, Carlile (2004) mentions the consensus of each function to generate common interest. The group decision-making theory states that consensus begins with the exchange of information, followed by repeated mutual influences that lead to uniformity. In mutual influence, there is often disconformity before finally returning to a new conformity. This phenomenon is in line with cynefin dynamics between complex domain and chaos domain, namely convergent and divergent. In the complex domain, the complete results of the investigation decide one form of pattern that is considered appropriate as the next emerging pattern (grounded theory). However, it does not close the possibility of the selected pattern to turns out to be inappropriate after seeing the development of the last situation, so it is necessary to look for alternative patterns (divergent entering the chaos domain chaos).

The phenomenon indicates that in pragmatic domains, there is a dynamic or displacement between complex domain and chaos domain over and over again. On this basis, Carlile (2004) divides the pragmatic domain into two, namely convergent pragmatic (complex) and divergent pragmatic (chaos). The pragmatic domain in question Carlile (2004) is a pragmatic convergent that aims to form common interest between functions, while in the divergent is colored pragmatic by the common force, which aims to find the appropriate pattern form as the basis for the formation of common interest. Thus, a proposition can be formed:

Proposition-4: In complex domains, knowledge is high tacitness and high specificity due to the increased complexity, and this is identical to pragmatic convergent domains. When tacitness and specificity are so high that causality is invisible, the domain is chaos, which is synonymous with pragmatic divergent.

\section{Responsive Model Identification}

After identifying each domain on the Cynefin model with causal ambiguity and pragmatic view, the responsive model definition becomes simpler. In known domains, which are syntactic, the common syntactic lexicon is obtained by simple transfer or information processing (Carlile, 2004), or acquisition (Zahra \& George, 2002). So the 'sense' stage is defined as understanding information, such as data, phenomena, or problems; 'categorize' is defined as searching prior relevant knowledge; and 'respond' is defined as transfer (retrieve) prior knowledge or information processing or acquisition new highrelated knowledge.

With the same analysis, the 'analyze' stage on knowable can be interpreted as searching the highest relevant knowledge; and 'respond' is defined as; translate or assimilation new knowledge. The thing that distinguishes is in the known domain. The relevance of prior relevant knowledge with phenomena or problems encountered is very high, whereas in the knowable domain tends to moderate. Therefore the chances of knowledge creation (Nonaka, 1994) are greater in this domain. Knowledge creation can be research, observation, laboratory testing, and so on.

When prior knowledge owned by the ACC organization is not able to predict the causality of a phenomenon, it shows that the possibility of the situation faced is complex or chaos. Chaos occurs when causality cannot be understood as the base end of the cause, and if causality is still understandable, then the domain is complex. The 'probe' stage in the complex domain is an investigative step towards the phenomenon that occurs and aims to form a pattern or potential pattern to develop towards problem-solving. The 'sense' stage is to understand the development of the situation in terms of the pattern by collecting new information, while 'respond' is transform, i.e., developing patterns with additional information. Unlike in ordered domains, the process on complex domains occurs again until the last pattern is found where the new information obtained does not provide additional insight into the pattern. When the last pattern was decided, the ACC organization 
managed to form new standard knowledge as a result of the transformation of prior knowledge. An identification summary of domain characteristics and responsive models is presented in Table 1 below.

In the chaos domain, hidden causality must be searched or searched by performing an action. This action needs to be done as quickly as possible because, in the event of a delay, it will cause an accumulation of ambiguity and chaos, resulting in collapse (chaos -> known). The reaction to the actions taken gives rise to evidence that allows the leader or expertise to see the pattern that was initially hidden. This is different from the complex domain, the complex where the action is taken after conducting a probe (investigation) and sense.

Absorptive capacity does not define this situation in its concept because it also takes the probe first. In contrast, the pragmatic view implicitly does not address it since it depend on sense, but according to the author, this domain is one part of the pragmatic boundary. In developing patterns when the domain complex or convergent pragmatic, there is often an increase in the tension of conflict between actors in it. This condition causes two impacts, positive and negative. The plus side is that there is an opportunity to find alternative patterns that may be better, and the downside is the collapse in finding new standard knowledge. The negative side can be minimized by strong leadership to stabilize the situation so that the actors have the common force to find the most suitable pattern. This is a divergent pragmatic domain, and therefore a proposition can be made:

Proposition-5: In the knowledge transformation process, there is always the possibility of pragmatic divergent, where strong leadership enlarges the common force towards convergent pragmatic (complex).

As mentioned, Cynefin dynamics is also able to explain the knowledge changes that occur in the organization. In Figure 6 above, the connection (a) is a change from the known and knowable domain that achieves incremental improvement aimed at improving the quality of knowledge, or in everyday terms, it is the quality of products and services (Cho \& Pucik, 2005). Improvement is also driven by the findings of a new pattern

Tabel 1. Summary of Concept Integration

\begin{tabular}{|c|c|c|c|c|}
\hline & $\begin{array}{c}\text { Known } \\
\text { (Syntactic) }\end{array}$ & $\begin{array}{l}\text { Knowable } \\
\text { (Semantic) }\end{array}$ & $\begin{array}{c}\text { Complex (Convergent } \\
\text { Pragmatic) }\end{array}$ & $\begin{array}{c}\text { Chaos (Divergent } \\
\text { Pragmatic) }\end{array}$ \\
\hline \multicolumn{5}{|c|}{ DOMAIN CHARACTERISTICS } \\
\hline $\begin{array}{l}\text { Cause-Effect Relationship } \\
\text { - Perceivableness } \\
\text { - Predictableness } \\
\text { - Repeatedness }\end{array}$ & $\begin{array}{l}\text { Define } \\
\text { High } \\
\text { Yes } \\
\text { Always }\end{array}$ & $\begin{array}{l}\text { Separate } \\
\text { Moderate } \\
\text { Yes } \\
\text { Often }\end{array}$ & $\begin{array}{l}\text { Intertwine } \\
\text { Moderate } \\
\text { No } \\
\text { Rare }\end{array}$ & $\begin{array}{l}\text { Hidden } \\
\text { Low } \\
\text { No } \\
\text { Very Low }\end{array}$ \\
\hline $\begin{array}{l}\text { Causal Ambiguity } \\
\text { - Complexity (+novelty) } \\
\text { - Tacitness (-specialization) } \\
\text { - Specificity (-interdependency) }\end{array}$ & $\begin{array}{l}\text { Define } \\
\text { High } \\
\text { Yes } \\
\text { Always }\end{array}$ & $\begin{array}{l}\text { Separate } \\
\text { Moderate } \\
\text { Yes } \\
\text { Often }\end{array}$ & $\begin{array}{l}\text { Intertwine } \\
\text { Moderate } \\
\text { No } \\
\text { Rare }\end{array}$ & $\begin{array}{l}\text { Hidden } \\
\text { Low } \\
\text { No } \\
\text { Very Low }\end{array}$ \\
\hline \multicolumn{5}{|c|}{ DOMAIN CHARACTERISTICS } \\
\hline $\begin{aligned} & \text { Cynefin Framework } \\
& \text { - Model approach } \\
& \text { - } \text { Key Activity }\end{aligned}$ & $\begin{array}{l}\text { S-Categorize-R } \\
\text { Processing }\end{array}$ & $\begin{array}{l}\text { S-Analyze-R } \\
\text { Hypothesize }\end{array}$ & $\begin{array}{l}\text { Probe-S-R } \\
\text { Emerge pattern }\end{array}$ & $\begin{array}{l}\text { Act-S-R } \\
\text { Search pattern }\end{array}$ \\
\hline $\begin{array}{l}\text { Pragmatic View } \\
\text { - Model approach } \\
\text { - United item }\end{array}$ & $\begin{array}{l}\text { Transfer } \\
\text { Common lexicon }\end{array}$ & $\begin{array}{l}\text { Translate } \\
\text { Common meaning }\end{array}$ & $\begin{array}{l}\text { Transform } \\
\text { Common interest }\end{array}$ & $\begin{array}{l}\text { Reform } \\
\text { Common force }\end{array}$ \\
\hline $\begin{array}{l}\text { Absorptive Capacity View } \\
\text { - Capabilities approach } \\
\text { - Prior related knowledge }\end{array}$ & $\begin{array}{l}\text { Acquisition } \\
\text { High }\end{array}$ & $\begin{array}{l}\text { Assimilation } \\
\text { Moderate }\end{array}$ & $\begin{array}{l}\text { Transformation } \\
\text { Low }\end{array}$ & Low \\
\hline
\end{tabular}


as a result of exploitation, namely the move from complex to knowable (b2). Organizations that focus more on quality than innovation will follow the path $\mathrm{a} \diamond \mathrm{b} 1 \diamond \mathrm{b} 2 \mathrm{a}$. Innovation is obtained when the $\diamond$ organization explores, i.e., the transfer from knowable to complex (b1) and/or perhaps through (c1) and (c2) before finally returning to the known domain through (d). Without crossing into the domain complex and returning to the known repeatedly, it is difficult for organizations to generate innovation towards SCA. This explanation is in line with the process of crossing the boundary into the pragmatic domain in a pragmatic view.

\section{CONCLUSION}

The Cynefin model provides a comprehensive understanding of the situation at hand, how the decision-making model should be, and the influence of dynamics between situations (domains). However, this model is general, requiring a more detailed description of the knowledge transfer process within the organization. Given that absorptive capacity and pragmatic view are more one-way iteration processes, the use of the Cynefin model as the basic framework for operating both knowledge transfer concepts above will provide a more detailed understanding for managers and practitioners in determining their decisions.

There are two common mistakes managers make, namely the failure to identify the domain of the situation and the mismatch of its decision -making process according to the situation at hand. This mismatch is generally due to the tendency of the manager to base his decisions on his prior knowledge. They prefer to analyze situations in the domain ordered causality, which is sometimes somewhat forced. Managers are often reluctant to commit exploration of unordered domains because they are limited by things like efficiency, big risk, or time. The greater the organization's reluctance to explore can lead to the slower growth of its knowledge, and the smaller the chances of generating innovation towards SCA.

\section{Theoretical and Practical Implications}

The models and concepts used in this paper are relatively new because they have only been published since the 2000s. The Cynefin model was developed by Kurtz and Snowden and was only published in 2003. Nowadays, it is widely used by researchers and practitioners to analyze the situation. The pragmatic view of knowledge has actually been developed by Carlile since 2002 but was later refined in 2004 .

The term absorptive capacity was first introduced by Cohen \& Levinthal (1990), which defined it as "the ability of a firm to recognize the value of new, external information, assimilate it, and apply it to commercial ends". During the 1990s, the development of the concept of absorptive capacity resulted in different dimensions and focus definitions. Therefore Zahra \& George (2002) combined everything, redefinition and conceptualization. The author considers Zahra \& George's research (2002) to represent the entire concept of existing literature so that it is representative enough to be used as one of the cornerstones of this theory. The only concept that is relatively long enough is causal ambiguity taken from Reeds \& Defilippi research (1990), supported by Simonin (1999), and used by some researchers such as stickiness of knowledge (Szulanski, 1996).

The merger of the above concepts is expected to have practical implications for managers in maximizing the Cynefin model. There are two advantages that can be obtained. First, because of its general nature, cynefin model is not easy to directly understand in certain contexts, for example, knowledge transfer needs particular understanding of some related topics. The integration of absorptive capacity and the pragmatic view can be used as guidance for managers to map each domain in cynefin model more specifically because they can also depict the integration points of those related topics. Second, the use of absorptive capacity and pragmatic view alone is perceived to provide less detail of the characteristics of the knowledge environment faced by the manager. For example, 
the pragmatic view distinguishes novelty as low, moderate, high. It will be more detailed when associating low novelty with known domains, or moderate novelty with knowable domains, and so on. Meanwhile, the absorptive capacity does not map the knowledge environment, except to say only the variety of knowledge source and trigger events (activation trigger) that can be incremental or radical.

According to Szulanski (1996), there are three most important factors that cause stickiness of knowledge, namely, causal ambiguity, absorptive capacity, and arduous relationship. The first two factors have been discussed in this paper. In contrast, arduous relationship, namely disharmony between functions within the organization, has not been explored further. In this regard, Bosch, Volberda, Boer (1999) has mentioned the combinative capabilities and organizational structure. However, it will be interesting to research what form of coordination is most effective in identifying cynefin domains and how they affect responsive models.

In addition, this research also opens up new space for further research, especially in the proving of the five propositions and/or the extension of the integration model. Carlile (2004) mentions that pragmatic views have never been empirically tested even though the concept is built on proven theories. Therefore, empirical testing of propositions in this paper will indirectly prove the pragmatic truth of the view of knowledge.

\section{REFEREN C ES}

Bosch, F. A. J., Volberda, H. W., Boer, M. (1999). Coevolution of Firm Absorptive Capacity and Knowledge Environment: Organizational Forms and Combinative Capabilities. Organization Science, 10(5): 551-568.

Carlile, P. R. (2002). A Pragmatic View of Knowledge and Boundaries: Boundary Objects in New Product Development. Organization Science, 13(4): 442-455.

Carlile, P. R., Rebentisch, Eric S. (2003). Into the Black Box: The Knowledge Transformation Cycle. Management Science, 49(9): 1180-1195.

Carlile, P. R. (2004). Transferring, Translating, and Transforming: An Integrative Framework for Managing Knowledge Across Boundaries. Organization Science, 15(5): 555-568.

Cho, H.J, Pucik, V. (2005). Relationship Between Innovativeness, Quality, Growth, Profitability, and Market Value. Strategic Management Journal, 26: 555-575.

Jensen, R. J., Szulanski, G. (2004). Stickiness and the Adaptation of Organizational Practices in Cross-Border Knowledge Transfer. Journal of International Business Studies, 35(6): 508-523.

Kurtz, C.F., Snowden, D. J. (2003). The New-Dynamic of Strategy: Sense Making in a Complex and Complicated World. IBM Systems Journal, 42(3): 462-483.

Nonaka, I (1994). A Dynamic Theory of Organizational Knowledge Creation, Organization Science, 5(1): 1437.

Reed, R, Defillippi, R.J. (1990). Causal Ambiguity, Barriers to Imitation, and Sustainable Competitive Advantage. The Academy of Management Review, 15(1): 88-102.

Simonin, B. L. (1999). Ambiguity and the Process Knowledge Transfer in Strategic Alliances. Strategic Management Journal, 20(7): 595-623.

Szulanski, G. (1996). Exploring Internal Stickiness: Impediments to the Transfer of Best Practice Within the Firm. Strategic Management Journal,17(Winter SI): 27-43.

Szulanski, G., Cappetta, R., Jensen, R. J. (2004). When and How Trustworthiness Matters: Knowledge Transfer and the Moderating Effect of Casual Ambiguity. Organization Science,15(5): 600-613.

Yin, R. K. (1991). Case study research: design and methods. Newbury Park, Rev. ed. 